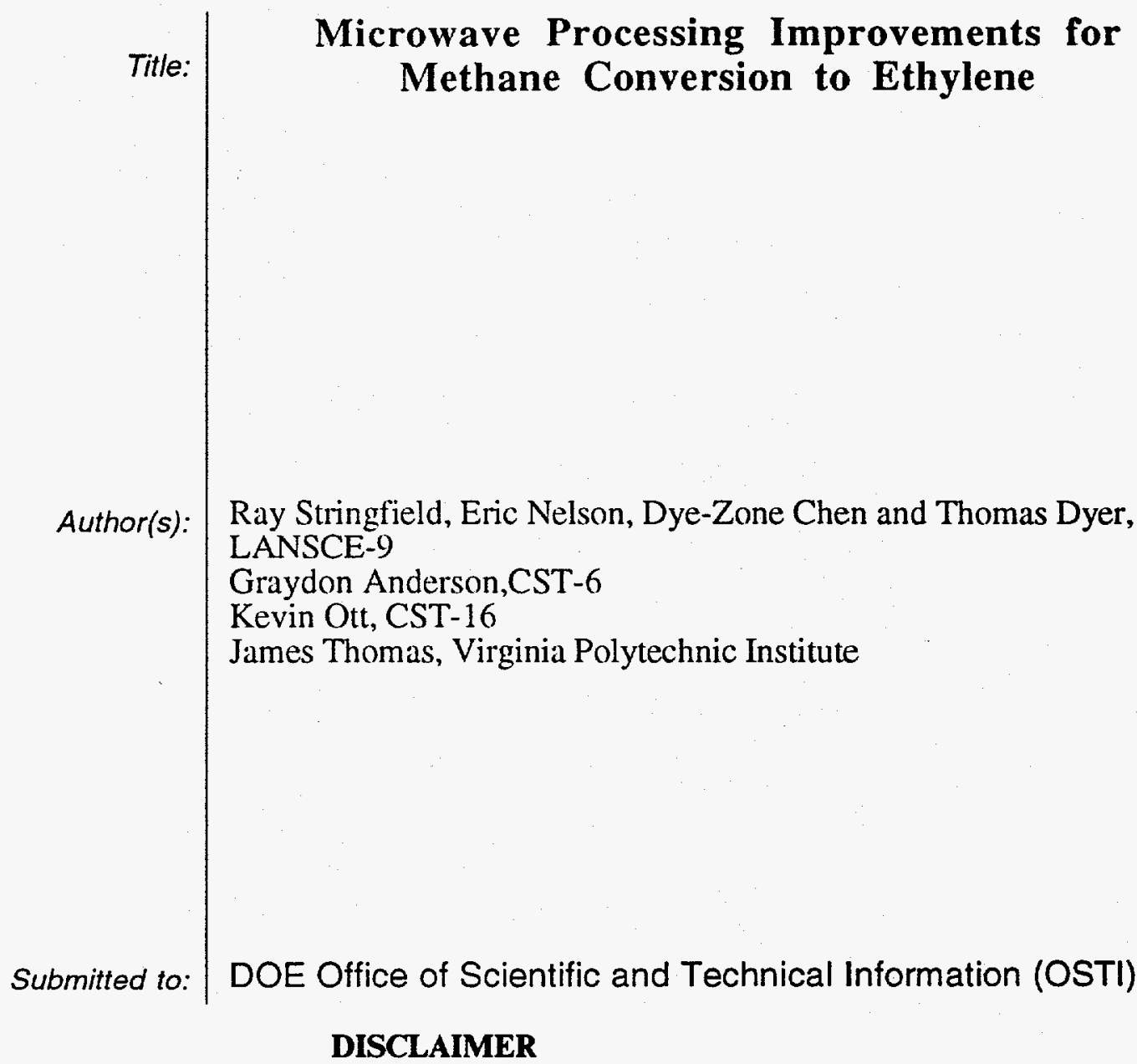

This report was prepared as an account of work sponsored by an agency of the United States Government. Neither the United States Government nor any agency thereof, nor any of their employees, makes any warranty, express or implied, or assumes any legal liability or responsibility for the accuracy, completeness, or usefulness of any information, apparatus, product, or process disclosed, or represents that its use would not infringe privately owned rights. Reference herein to any specific commercial product, process, or service by trade name, trademark, manufacturer, or otherwise does not necessarily constitute or imply its endorsement, recommendation, or favoring by the United States Government or any agency thereof. The views and opinions of authors expressed herein do not necessarily state or reflect those of the United States Government or any agency thereof.

Los Alamos National Laboratory, an atfirmative action/equal opportunity employer, is operated by the University of Calitornia for the U.S. Department of Energy under contract W-7405-ENG-36. By acceptance of this article, the publisher recognizes that the U.S. Government retains a nonexclusive, royallyfree license to publish or reproduce the published form of this contribution, or to allow others to do so, for U.S. Government purposes. Los Alamos National Laboratory requests that the publisher identity this article as work pertormed under the auspices of the U.S. Department of Energy. Los Alamos National Laboratory strongly suppons academic freedom and a researcher's right to publish; as an institution, however, the Laboratory does not endorse the viewpoint of a publication or guarantee its technical correctness. 
DISCLAMMER

Portions of this document may be illegible in electronic image products. Images are produced from the best available original document. 


\title{
Microwave Processing Improvements for Methane Conversion to Ethylene
}

\author{
Ray Stringfield*, Kevin Ott, Eric Nelson, Graydon Anderson, \\ Dye-Zone Chen and Thomas Dyer \\ Los Alamos National Laboratory \\ James Thomas \\ Virginia Polytechnic Institute
}

\begin{abstract}
This is the final report of a one-year, Laboratory Directed Research and Development (LDRD) project at the Los Alamos National Laboratory (LANL). The project's objective was to investigate microwave enhanced catalysis. Published work by others had demonstrated improved selectivity in microwave-driven catalytic conversion of 2-methylpentane to its isomers. We reproduced their experiment, discovering that there is no improvement in selectivity using microwaves. The selectivity at a given conversion was the same for both microwave heated and conventionally heated catalyst beds. Meetings with the authors of the previously published work led to the conjecture that their catalyst was not being prepared properly, leading to anomalously low selectivity for their conventional heating runs. An optical temperature diagnostic suitable for use on a microwave applicator was developed and characterized in this project. This pyrometer can measure the temperature of small scale features on the catalyst bed, and it has a fast response that can follow the rapid heating often encountered in a microwave processing system. The behavior of the microwave applicator system was studied, and theoretical models were developed to yield insight about the stability and control of the system.
\end{abstract}

\section{Background and Research Objectives}

Microwave-driven catalysis has demonstrated great potential for a number of commercially viable products and processes. A well-publicized example is a DuPont process to make HCN (hydrogen cyanide) in a small (10- to 15-foot square) plant that is located and operated at the user's site. The microwave process allows $\mathrm{HCN}$ to be created on demand. This combination greatly reduces transportation and storage hazards. It also reduces costs.

The impact of microwave technology in the chemical industry is growing.

*Principal Investigator, e-mail: stringfield_r@lanl.gov 
Chemical manufacturing is directly tied to approximately $30 \%$ of the US economy, and microwave technology will likely be employed in a significant portion of this industry in the future.

This project's research objective was to develop a fundamental understanding of microwave-driven catalysis in a process relevant to industry: the selective oxidation of methane to ethylene. This particular process was chosen after initial discussions with DuPont indicated it was relevant and highly visible. Conventional (non-microwave) technology is limited to less than $25 \%$ conversion due to the destruction of the product in the hot gas phase. This limited conversion makes generation of liquid fuels from methane economically unfeasible. Microwave technology, with its unique heating distribution that can keep the gas phase cool, can likely provide better than $25 \%$ conversion. This could make liquid fuel generation from methane economically attractive.

Before pursuing the selective oxidation of methane to ethylene, a benchmark reaction was chosen for study: the isomerization of 2-methylpentane. Dow Chemical and DuPont were interested in reviewing some previously published work, which had demonstrated that microwave processing improved selectivity of 2-methylpentane isomerization. Reproducing this work would break in our multi-disciplinary team, verify the operation of our microwave processing equipment and diagnostics, and establish our credibility in the microwave processing community.

This project's program development objective was to raise the visibility of our multidisciplinary programs in the microwave processing community in order to attract further funds-in work from the large chemical corporations. Maintaining a program in microwave processing also facilitates a rapid response to the needs and concerns of US industry. Both DuPont and Dow Chemical have expressed interest in collaborating with Los Alamos on the exploration of microwave processing.

\section{Importance to LANL's Science and Technology Base and National R\&D Needs}

This project employs and develops a number of Los Alamos' core technical competencies. The microwave processing experiments require advanced optical temperature diagnostics. These diagnostics must observe temperature variations on a small length scale (e.g., distinguish the temperature of a small platinum catalyst bead from the temperature of the surrounding alumina substrate) and on a fast time scale inside a microwave reactor environment that is hostile to many temperature sensors. Thus, this project employs and develops the Laboratory's complex experimentation and measurements core technical competency. 
Design of the experimental apparatus and interpretation of the results requires careful and accurate modeling of a complex system. This modeling includes electromagnetic, heat transport, fluid flow and chemical simulation. Accurate electromagnetic modeling is important because the microwave radiation drives the temperature of the reactor, and small variations in the temperature can lead to significant changes in the chemistry. Thus, this project employs and develops two other Laboratory core technical competencies: theory modeling and high performance computing and analysis and assessment.

Microwave processing is a tool for constructing advanced materials and characterizing materials in general. Thus, this project develops and employs the Laboratory's nuclear and advanced materials core technical competency.

This project involves electromagnetic modeling of microwave applicators, which is similar to the modeling work performed by the Los Alamos accelerator community (e.g., for the Los Alamos Neutron Science Center and the Accelerator Production of Tritium project). It also employs and develops microwave components, diagnostics and control systems that are similar to those used in accelerator work. Thus, this project employs and develops the Laboratory's nuclear science, plasmas and heams core technical competency.

This project is relevant to the research and development needs of the US chemical industry, as discussed in the previous section.

\section{Scientific Approach and Accomplishments}

This project investigated a report [1] that microwave processing improved the selectivity of isomerization of 2-methylpentane by platinum-alumina catalyst. Our experiments carried 2-methylpentane in hydrogen gas over a platinum-alumina catalyst. The catalyst was heated by one of two means: conventional heating in an electric oven or microwave heating in a microwave applicator. The catalyst temperature was monitored by optical temperature diagnostics and/or thermocouples. Experiments were performed at various catalyst temperatures, heating methods and flow rates. The products were analyzed using a gas chromatograph. Concentrations of hexane isomers (2-methylpentane, 3methylpentane, $n$-hexane and methylcyclopentane) and cracking products were measured. Prior to an experimental run, the catalyst was prepared by calcination (with oxygen) and reduction (with hydrogen) at various temperatures.

Contrary to the published report, our work showed no special microwave effect in this chemical process. Details of our results can be found in [2]. Comparing selectivity versus conversion, there is no significant difference hetween microwave heating and 
conventional heating. Our selectivity measurements agreed with the high selectivity published for the microwave heating case. However, we did not observe low selectivity for the thermal heating case. Following meetings with one of the authors of the published articles (Roussy), this discrepancy was attributed to inadequately controlled preparation of the catalyst before the experimental runs of the published work. In [1], the conventionally heated catalyst was incompletely calcined, while the microwave heated catalyst was fully calcined. In our work the catalyst was fully calcined for both heating cases.

We hegan experiments to verify the effect of incomplete catalyst preparation on the selectivity of 2-methylpentane isomerization. Conventional heating runs with the calcination step performed at reduced temperatures and times were performed. Unfortunately, the project funding was consumed before this work could be completed.

Our experiments employed scanning infrared cameras, optical pyrometers, fiber optic temperature probes and thermocouples. An optical temperature diagnostic was developed and characterized during this project [3]. This diagnostic is capable of measuring the temperature of a small location (e.g., a small hot spot) on the surface of the catalyst bed. It also can follow rapid changes of the temperature (e.g., due to initiation of microwave irradiation). This diagnostic was characterized and compared with other commercial temperature diagnostics.

A new microwave applicator was constructed for this project. It includes reactor tube ports that accommodate a smaller diameter reactor tube than our previous applicators. The applicator includes an optical port perpendicular to the reactor tube and waveguide. The ports incorporate metal microwave cutoff-tubes to prevent microwave leakage. A technique to measure the electric field in the vicinity of the reactor tube was developed to study and control the microwave coupling and heating. This technique was important for optimizing the microwave power coupling in a more recent microwave chemistry effort (a funds-in agreement with Dow Chemical).

Theoretical investigations of heat transfer in microwave applicators were made in collaboration with Prof. Jim Thomas and one of his students. The effect of radiative heat transfer [4] and fluid convection through a catalyst bed [5] were studied. Prof. Thomas received an NSF grant for 1997. His proposal includes collaboration with Los Alamos in order to experimentally verify his theoretical models of microwave heating of metal oxide catalysts.

The stability of the microwave applicator system was studied near the end of this project, and a conference paper was published on the subject (see publication below). A theoretical model of the system provided insight about the behavior observed in our 
system. This model also provided insight about how to better adjust and control the system.

\section{Publication}

Nelson, E. M., "Enhancement of Thermal Stability in Microwave Applicators by Mismatching and Detuning," Proceedings of the 31st Microwave Power Symposium, pp 108-109 (1996).

\section{References}

[1] Seyfried, L., et. al., "Microwave Electromagnetic Field Effects on Reforming Catalysts: I. Higher Selectivity in 2-Methylpentane Isomerization on Alumina-Supported Pt Catalysts," Journal of Catalysis, 148, pp 281-287 (1994).

[2] Chen, D. A., "Microwave Chemistry Report," AOT-9/LANL unpublished report, Dec. 23, 1995.

[3] Anderson, G. K., "The Effect of Surface Emissivity on Spot Pyrometer Performance," CST/LANL unpublished report, May 30, 1996.

[4] Roos, R. M., "Radiative Effects on the Calculation of the Temperature Distribution Within a Catalyst Bed Inside a Quartz Tube," AOT-9/LANL unpublished report, July 1996.

[5] Roos, R. M., "Velocity Profile Effects on the Calculation of the Temperature Distribution Within a Catalyst Bed Inside a Quartz Tube," AOT-9/LANL unpublished report, Sep. 1996. 